\title{
The Students, the Local and the Foreign: Drama of Identity and Language in Mongolian-English Bilingual Schools
}

\author{
Flora Komlosi-Ferdinand \\ University of Wales Trinity St David \\ Correspondence concerning this article should be addressed to Flora Komlosi-Ferdinand, University of \\ Wales Trinity St David, Carmarthen Campus, Carmarthen, SA31 3EP, United Kingdom. \\ E-mail: flora.komlosi@yahoo.co.uk
}

\begin{abstract}
Education in bilingual schools aims to equip learners with balanced bilingualism, increased (bi)cultural capital and a global mindset. Nevertheless, in a growing number of countries only local children attend such institutions, where foreign teachers are the almost exclusive manifestations of 'globalness'. Dynamics among foreign and local teachers and students shape learners' attitudes, their learning outcome and identity formation to an unexpected degree. This often produces unhealthy perceptions and behaviour in the classroom, eventually resulting in students not benefiting from bilingual education to the expected extent. One of the oldest and one of the newest bilingual schools in Ulaanbaatar, Mongolia, were observed for this study. Local and foreign teachers of these schools contributed with their experiences in the form of unstructured interviews, while classroom observations shed light on students' attitudes. The findings reveal that students respect local educators more and display more respect and discipline with them. However, pupils are usually more emotionally attached to foreign teachers, confiding in them and seeking their company on a daily basis, yet refusing to be disciplined and to study for their classes. Students' unbalanced attitudes towards the two groups of teachers generated unease between the educators as well. This paradox created an unhealthy milieu in the schools and discouraged the development of a healthy perspective on (foreign) languages and identity. Teachers' attitudes further compromised learners' behaviour, as local educators stressed nationalism, while foreigners pressed towards the development of a more global mentality. Unfortunately, as none of the institutions had any policies to address this dilemma, eventually students developed behaviours contrary to the intended by the schools.
\end{abstract}

Keywords: bilingual schools, language and identity, foreign teachers, student attitudes, Mongolia

\section{Introduction}

The present investigation aims to decipher how Mongolian students' identity is shaped or further conditions their attitudes and social-emotional responses towards foreign and local teachers in English-Mongolian bilingual schools. The rapidly growing Mongolian economy nurtures the opening of new bilingual schools on a yearly basis (May, 2009). Parents with increasing wealth prefer to secure a more global education for their children, placing substantial importance on foreign language education, foreign curricula and cultural capital, defined as giving priority to life's cultural and intellectual assets as opposed to material ones (Bourdieu 1990, Weininger, 2003; Weenink, 2008). Among the objectives of bilingual education, there is the formation of both linguistically and culturally fluent students in Mongolian and in the foreign language, in the case of this study, English. While this idyllic scenario may be a challenge in itself, parents often enrol their offspring at a later age (sometimes at fifth grade or later) and envision their children to catch up with the rest of their peers only in a school term. Often, this proves to be an emotionally and foreign-language wise overwhelming situation (Milosevic, 2019). Standard international schools in Ulaanbaatar with full English curricula have monolingual teaching, that is, regardless of the nationality of the teachers, all subjects are taught through the medium of English (Bunnell, 2019). A few bilingual schools, however, offer a balanced number of teaching hours both in English and in Mongolian (Hill, 2015). The cultural landscape of these schools varies, most of the educators being local with some additional foreign teachers and (sometimes) administrators from different countries. 
The number of foreign staff strongly varies among schools (Meneghella, Walsh \& Sawagvudcharee, 2019), and a great number of cultural differences and attitudes towards teaching can be observed between the local and the foreign educators (Dos Santos, 2019). This considerably asymmetrical panorama activates observably different social-emotional responses from the mostly Mongolian students towards both groups.

\section{Mongolian Society}

Mongolia is a vast landlocked country situated in Central Asia, bordered by China and Russia. Although Mongolia's territory counts among the biggest in the world, its population is tiny, barely exceeding three million inhabitants, half of them being concentrated in the capital city, Ulaanbaatar (also spelled Ulan Bator). While Khalkha Mongol, the Mongolian dialect spoken around Ulaanbaatar, is the only official language of the country, Kazakh and other minor languages are spoken in different regions of the country. Mongolian is a rapidly changing society. Although the traditional social structure constituted of nomadic, herding families, is still revered and practiced in the countryside, the inhabitants of the capital and the two bigger cities, Darkhan and Erdenet, have undergone unprecedented economic growth and modernisation in the past decades (May, 2009; Hanson, 2004; Sarlagtay 2002). Between 1941 and the end of the communist era in the 1990's, the mostly illiterate Mongolian society became 93\% literate and educated. The Mongolian communist government emphasised and provided education not only for children but for adults as well, this paving the way for a healthy wish and routine of education for the following decades (Hanson, 2004; May, 2009).

Nowadays, middle class and rich Mongolians travel abroad and believe that international education for their children is a basic requirement for a successful life. Nevertheless, many of the ancient elements of their culture are still practiced in everyday life, such as obedience towards the elders, the daily use of deel, the Mongolian traditional clothes, and rituals such as throwing milk in front of their houses in the morning for having luck. (Hanson, 2004). This creates a particularly interesting scenario in the country's bilingual school system, where both tradition and global mindsets coexist in a non-linear fashion. Although Mongolia during its history of invasions and being invaded has experienced many foreign cultures, it can be said that the Mongolian society has remained fairly isolated in its mentality and educational practices (Komlosi-Ferdinand, 2019; Hanson, 2004). Despite the fact that Mongolians continually try to globalise themselves, change does not come at a speed expected (Hanson, 2004). This is well reflected in the Mongolian educational scenery as well. Although schools and universities try to implement new and modern strategies, the already existing teaching and administrative structures still flourish. This can be observed at schools where the often low-morale of some teachers frustrated by the working conditions adds to the tense educational panorama (Rossabi, 2005). Additionally, in the educational context, corruption has become a serious problem, as students (or their parents) can forcefully demand better grades or special treatments from the educators (Hanson, 2004). This practice is extremely dangerous for Mongolia's new developing intellectual capital and international outlook. The question remains to what degree this ideology affects education in bilingual schools and learning attitudes and outcomes among students aiming for a more global lifestyle.

\section{Literature Review}

\section{Identity and Emotions}

As bilingual education is becoming more widespread, there is an existing concern at school and parental level about its outcome regarding learners' developing identities, world-view and their ability to maintain their cultural heritage (Heyworth, 2004). Fearon (1999) describes the term identity as the two strongly intertwined concepts of personal and social interpretation of ourselves that clarify an individual's concept about himself/ herself and how he/she wants to be perceived by others. According to Sarlagtay (2002), the sense of identity in Mongolia has developed a troubled issue over the last decades. This became very apparent from the early 1990s, when Mongolian people started to reclaim their national identity and traditions, stating that 'excessive liberal cosmopolitanism is the current face of Mongolia. It has had negative results in Mongolian society today, which diminish national feeling and ignore patriotism among the population. If rising liberalism might be example of the opportunistic and adaptive ability of Mongolians, but it is harmful for Mongolia's existence as a nation' (Sarlagtay, 2002, p, 103). As a result, Cohen (2004) points out that in the educational setting Mongolians often have doubts whether the foreign teachers' backgrounds, culture, ideologies and teaching styles will not interfere with 
students' developing patriotic spirit. He further states that in order to prevent the foreign influence, in the early 2000s there was a clear intent to create a 'Mongolian English', which would only focus on using English language as a communication tool without the immersion in its cultural elements and language-related social features. Although this proposal has never become official, yet its message has deeply infiltrated into the Mongolian education system. Furthermore, Khongorzul, a professor interviewed in Cohen's study declared: 'If the popularity of English grows any more, it will become a virtual second language among our younger generation' (Cohen, 2004, p. 21). As seen, the duality between preserving the national identity and globalising their mentality is an ongoing discussion among Mongolians. This article further discusses how the younger generations' emotions and self-definition can subsist in such context.

Komlosi-Ferdinand's (2020) recent study on academic emotions in the Mongolian classrooms draws attention on how Mongolian students' emotional state and learning outcome is heavily conditioned by the teachers' attitudes, emotional validation, and the classroom environment created the educator. Moreover, she states that 'Acknowledging and considering students' emotions may lead to a healthy power structure and balanced milieu in the classroom where most of the academic emotions may be turned and used as motivational agents' (KomlosiFerdinand, 2020, p. 16). Similarly, Butler (2019) points out, that emotions and cognition are now inseparable entities in successful learning. Swain (2013, p. 195) reinforces this thought by stating that 'emotions are an integral part of cognition'. Therefore, as learners associate a different degree of discipline and distinct emotional states and communication models with both groups of teachers, in consequence, contrasting classroom scenarios, student-teacher power structures and learning dynamics can be observed in the classrooms. This differentiation may have a profound effect on the learning success and the emotionalbehavioural landscape of the whole school. Furthermore, once these patterns of attitudes become fossilized, they mould learners' perspectives on cultural sensitivity and on the social-emotional-intelligence rooted in both languages (Komlosi-Ferdinand, 2020). Moreover, Hill (2018) highlights that students' actions, behaviour and social reality is built upon the perception and interpretation of past events. Thus, negative experiences may considerably harm students' future prospects, as the intended goal in attending bilingual schools is often to secure a place in foreign higher education institutions. Wang's (2012) study draws attention on how 'new rich' Chinese students from high cultural capital families prioritise knowledge acquiring, eventually becoming globally educated and socio-culturally intelligent individuals, while learners from medium cultural capital upbringing mostly wish to ensure a good diploma from foreign universities in order to build a career and economic status. However, low cultural capital families' intellectual journey ends with the child being accepted to a university and eventually acquiring the diploma, which will be of no further use except taking pride in it as a decorative element. Hence, comparing students' attitudes and social-emotional responses towards both groups of teachers may help to develop some new strategies and policies that would benefit in educating real 'internationally minded' and 'global citizens' at these institutions (Tanu, 2016).

\section{Symbolic Violence and Habitus}

Pierre Bourdieu's several works may have great impact on bilingual schools' organizational practices, as in such institutions, languages (mother tongue and foreign language) are not simple communication tools or school subjects but they correspond to identities, social space and status. Bourdieu (1996, p. 22) claims: 'the social space is indeed the first and last reality, since it still commands the representations that the social agents can have of it'. Moreover, Bourdieu's (1990b) 'habitus theory' highlights how a value system established by the individual's social background will condition and operate further thoughts, perceptions, responses and activities in the everyday life. In the case of students attending bilingual schools, the particular significance of this lies in the two clearly differentiated groups of local versus foreign teachers and the social spaces and status attributed to them. The two groups of teachers may be differentiated in multiple levels, such as local and foreign, higher and lower social space, or high and low intellectual capital, defined as the individuals' knowledge, skills and experiences that can be used as a currency in a variety of interpersonal and workplace related contexts (Tamer, Dereli \& Sağlam, 2014). Students' attitudes towards these groups, therefore, will shape not only their education, but the development of their own social spaces, sensibility, intellect and identity (Sweeney, 2017). Moreover, Bourdieu's (1998) symbolic violence theory draws attention to the fact that in most domains, two coexisting social spaces necessarily experience power-plays, the establishment of hierarchy, and in some cases (symbolic) violence. Symbolic violence is described as a psychological and non-physical force executed by the higher social classes, whose norms are often unquestionably and automatically accepted. Furthermore, throughout his life Bourdieu maintained the notion that intellectuals will necessarily constitute part of the 
'ruling class', or dominant social space, because of their cultural capital (Bourdieu 1990; Weininger, 2003). As the two social spaces are necessarily given at bilingual schools, it is vital to unveil the specific factors on which the hierarchy is established and whether it is linear and stable throughout all domains and contexts.

\section{Language and Power}

'Language is used to demonstrate power in numerous contexts and power too is used to give language a particular meaning in a particular context' (Pătraşcu \& Allam, 2017, p.168). This statement is reinforced by Ashcroft, Griffiths and Tiffin (1989), who state that language can and does metamorphose into an instrument via perceptions and consciousness of 'truth', 'power' and 'reality' become confirmed and accepted. Moreover, according to Arazzi (2014), language is an ability distinctive to humans, which creates and moulds our perception about 'reality'. Nevertheless, she also points out that this 'reality' is constantly affected and impacted by the individual's circumstances and environment. Similarly, Jørgensen (2006) states that instead of perceiving language as the final organisational system of reality, it is, in fact the tool to create this desired state. Furthermore, Fairclough $(1989$, p.3) declares that 'language has become perhaps the primary medium of social control and power'. These definitions reveal well the depth of how a language may be used to converge, diverge or manipulate ideas and events in contexts where multiple languages and identities coexist. Moreover, how a language is spoken, read, written and interpreted impacts the individual's self-perception and social standing (Fairclough, 1989). This is particularly true in multilingual schools. Fairclough (1989) points out how school's 'hidden agendas' use discourse and power to shape perceptions on social structures and social classes. Ultimately, Lewin's (1951) force-field theory discusses how two major factors, driving and restraining forces affect either positively or negatively events moving toward the desirable direction or goal. This phenomenon represents well the delicate equilibrium among languages and identities in bilingual schools, while the identity of the driving forces and restraining forces is yet to be determined when applied to students.

\section{Research Questions}

It is safe to say that in Ulaanbaatar, most bilingual schools strive for balanced outcomes in their education. Furthermore, they offer a new, global perspective on foreign language learning and use for personal development, as well as try to promote a more open society. These new perspectives often take shape in foreign teachers, as they are viewed as 'ambassadors' of foreign lands, allowing insight into a variety of cultures and customs often perceived as relevant in order to understand better the socio-cultural context of the foreign language taught. However, these educators' socio-cultural background and sometimes unfamiliar behaviours and teaching styles from the viewpoint of the local students may provoke unexpected attitudes and teachinglearning dynamics between students and teachers (Heyworth, 2004). The researcher's perception was that Mongolian pupils become confused by the [often drastically] different teaching styles of foreign educators, which, in turn, undermines their attitudes towards both the local and foreign teachers. Moreover, pupils associate language and identity with very specific behavioural styles, creating an unhealthy emotional milieu at the schools. In the light of this, two research questions were investigated:

1. Does identity play a role in Mongolian students' perception on different levels of power and respect towards foreign teachers as opposed to locals?

2. What linguistic and cultural factors shape students' identity in bilingual schools?

\section{Methodology}

\section{Research Context}

As Cohen, Manion and Morrison (2018) point out, understanding and researching a situation often requires long-term immersion in the system. Moreover, as all factors, rather than a limited number of variables, have to be taken into account in understanding a phenomenon, the methodology chosen for this study was qualitative research through observation, both in class and outside the class, to analyse the key factors that may influence learners' behaviour from societal and linguistic viewpoints. In addition, in order to have a more in-depth view, the researcher collected data on a weekly basis in the form of unstructured interviews with English-speaking and non-English speaking teachers (some of them acting as administrators as well), and students. Content 
analysis was applied to all the data. The observation and interviews happened between the $1^{\text {st }}$ of September 2018 and the $1^{\text {st }}$ of December 2019.

\section{The Participating Schools}

The investigation took place in one of the first English-Mongolian bilingual schools of Ulaanbaatar, with 25 years of history of bilingual teaching, and in a newly opened bilingual school with the same curricula. The number of pupils in the first school was around 800, while the second school had around 300 students at the time of the research. The ratio of local teachers to foreign teachers was 90:10 in both schools. Both institutions' educational policy can be classified as a strong form of bilingual education for bilingualism and biliteracy according to Baker (2011). These schools were particularly suitable for the investigation, since, although being bilingual schools, approximately $95 \%$ of the students in both of them were Mongolian native speakers whose socio-economic backgrounds were very similar. Therefore, the attitudes displayed were not biased by different cultural influences.

\section{Participating Teachers and Students}

A total of 27 English speaking teachers (foreign and local) in both schools were involved in the investigation. In addition, some of the participating bilingual teachers regularly helped with data collection from the nonEnglish speaking teachers by translating or interpreting their contributions. There was no restriction on the teachers' subject, since the attitudes towards teachers' nationalities were investigated. The foreign teachers were from North America (9), Russia (2), Western Europe (4), India (1) and Australia (1). Of them 11 held at least an MA. The rest also had BAs and teaching diplomas. None of the teachers were volunteers. Of the English-speaking Mongolian teachers, 7 held at least an MA while the other three had BA in different fields. Amongst the 9 non-English speaking educators, all of them were qualified teachers, attending duties as both classroom and subject teachers.

In total, 11 groups and approximately 320 students were observed. As some students left throughout the year and some new came, the number of students observed was not exact. The older students (from fifth to eleventh grade) were particularly happy to collaborate, 28 of them sharing their thoughts in a very open fashion during the class observation and informal interviews.

\section{Procedure}

All data were recorded by taking notes during the weekly meetings with the teachers, unless they had some particular stories during the week (which happened very often both on the local and foreign sides). The class observations and the out-of-class (often informal) interactions with the students were recorded by taking notes on a daily basis (Wragg, 1978, 1999). All teachers and the older students were conscious of the aim of research. All information was shared on a voluntary basis and clear consent was given to observe their classes. In the case of the younger students, who were not able to understand the concept of the present research, the local teacher explained it in Mongolian and with simplified terms. When observing the younger students, the classroom teachers' permission was obtained, as they are fully authorised by the parents to make any decision regarding the pupils during school hours. The data were coded by selective coding, as described by Cohen, Manion and Morrison (2018) and analysed by clustering units by relevant content and meanings (Hycner, 1985).

The data, being qualitative, required an inductive analysis. This encompassed reading, reflecting on, inferring from and interpreting the raw transcripts. From this process, the researcher developed interpretations of the data and derived explanations and understandings which fairly and comprehensively explained the phenomenon (Thomas, 2006; Cohen et al., 2018).

\section{Results and Discussion}

The present study investigates Mongolian students' perceptions and behaviour towards foreign and local teachers and the educators' attitude, while aiming to unveil how students' language and identity formation is 
affected by both groups. The findings based on the interviews and observation identify significant contrasts in learners' attitudes towards local and foreign teachers. The study also identifies some interesting points in teachers' attitudes which may incite counterproductive behaviour in students, leading to confusion about how their national identity and their new global perspective should be balanced. The first research question shed light on how students' perceived identity is shaped by the level of power and respect they attributed to the local and foreign teachers.

\section{Observations}

During the classroom observations, it was impossible to precisely and adequately measure teacher-power exercised, yet comparing the lessons of both local and foreign teachers, the results show that pupils are considerably more respectful and obedient towards the local educators. It became obvious that learners of all ages have the utmost fear of Mongolian teachers, displaying flawless obedience and submission towards them. During the local teachers' lessons, homework and projects were delivered properly and on time, without ever questioning the amount, aim or 'compulsoriness' of it. On the other hand, students would constantly find more or less subtle ways to express their general dislike for local teachers as often and openly possible. Among these, the usage of negative body language (that would suggest resistance), specific noises (sighing loudly) and sometimes insulting them in English whenever they perceived not to be understood were regularly observed. This scenario caused much distress for the teachers, which, in turn, provoked their anger and they exercised even more pressure on the students. Nevertheless, this form of classroom management resulted in optimal attitudes towards learning and intense eagerness to succeed during the lessons and exams.

The general approach towards foreign teachers was manifested mostly in the opposite fashion. Learners often and openly displayed affection both physically (hugs) and verbally by shouting in the classrooms and corridors the degree of love they feel for most of them. The company and coaching of foreign teachers were often preferred, and pupils made extra efforts to connect with them on the social media as well. However, during the teaching and learning part, an extreme paradox could be observed. The foreign teachers may have already started the class, yet many of the students perceived no reason to stop interacting loudly, walking in the class, or even leaving the premises during the lessons. In general, discipline was completely inexistent in the classes, regardless of how much the foreign teachers tried to achieve it. Homework and projects were very seldom done, and the notebooks were regularly left at home (if they ever existed or used for the intended purposes). Additionally, two other interesting facts surfaced during the foreign teachers' lessons. The first one being that, although the foreign teacher explicitly asked silence in the classroom, students limited this request only to speaking English, yet they freely continued their discussion in Mongolian. When the teachers expressed anger and explained that silence meant the total avoidance of emitting sounds in any language, students regularly, week after week acted surprised declaring that they were not actually speaking. When the foreign teachers requested an explanation about this behaviour, students seemed perplexed, and some of them insulted the foreign teachers in Mongolian, thinking that they wouldn't be understood. This proved to be quite unfortunate, since some foreign teachers were fluent in Mongolian. At that point, teachers would reply to them in Mongolian, making it clear that they understood the insult and it was inappropriate to say such things. Following a short silent moment caused by the surprise, students would switch language and would mostly try to speak Mongolian to the teacher or finding new ways to mimic the teachers' accent and tease them about it. Nevertheless, as both schools' policy forbade foreigners to speak any Mongolian in the classroom, learners were simply asked to switch back to English. The fact that students realised that some foreigners could speak their language, caused no change in their attitude towards them. Apparently, if foreigners had some power in the classroom, this happened exclusively regarding the English language.

\section{Students' Opinions}

The learners' viewpoints were very uniform. As voiced by a ninth-grade student during the interviews, pupils' attitudes towards Mongolian teachers are shaped this way mostly due to wanting to gain their 'mercy' and to 'navigate easier between the unrealistic expectations of the teachers'. A fifth-grade student commented laughing: 'Well, it's all about survival... Mongolian teachers are very scary'. This declaration was passionately confirmed by his peers, and can be linked to their regularity in doing and submitting projects and homework, since according to them, this is a must, otherwise the local educators will be 'very, very angry'. Some of them even stated that 'Mongolian teachers can hurt us'. This is not intended to understand literally. Learners explained that because of local teachers being knowledgeable about locally acceptable forms of verbal and psychological discipline, the menace seemed imminent and real to them. As a student expressed: 'My teacher will 'kill' me if I don't behave 
well and finish my homework. Later she will call my mother about it, and she and my father will punish me very hard'. The most often voiced idea by the students referring to their local teachers is the most descriptive of all: ' $S / h e$ is Mongolian...S/he is strong... We Mongolians-switching automatically to plural-are strong.' The continuous mantra of this idea has strongly suggested students' perception about Mongolian teachers and Mongolians in general to have a 'strong identity and strong will' as a nation and individually as well. When students were enquired about their behaviour with foreign teachers, the overwhelming majority agreed that as opposed to Mongolian teachers who cause emotional stress and treat students in a too 'strict' and 'humiliating' way, foreigners were 'weaker', 'kinder' and 'funnier'. Moreover, the vast majority of students felt that lessons with foreigners were 'less disciplined', 'more outgoing' and 'emotionally 'more accommodating'. According to them, they never realized that this might be disrespectful. They perceived foreigners being 'cooler', therefore, they believed it was appropriate to behave 'cooler' too. Thus, according to many of them, there was no need to prepare or submit the foreign teacher's homework on time, in fact the overwhelming majority in all grades saw no need to do any homework assigned by the foreign teacher at all. In the view of a sixth grader 'Foreign teachers are nice, because we don't have to do anything in their lessons.' Another sixth grader added: 'We do what we want, there will be no consequences, but they will give as good grades anyway.'

In the Mongolian teachers' opinion, students disciplined behaviour was the basic norm in their classes, being this the expected teacher-student power structure, which gives the foundation of Mongolian society's behavioural hierarchy. As echoing the voice of the majority, a local teacher commented: 'The reasons for this student behaviour in the classroom lays in our [Mongolian] culture. Here in Mongolia, it is a country-wide accepted belief to push children further than their capacity, to overload them with endless pages of homework, to openly humiliate them in front of each other and to completely disregard students' emotions and their specific circumstances. When students want to talk about emotions, problems with their families or learning difficulties, we just tell them to stop complaining'. Other local teachers stated that at the expense of sounding too harsh, their love for children has nothing to do with the strong discipline they applied in the classroom: 'It is just how it have to be'. Nonetheless, local teachers were still unhappy about the degree of discipline and respect displayed by the students towards them. Their most often voiced complaints were 1) children being completely spoiled by their parents and, 2) foreign teachers' often less formal teaching style corrupting the students' proper attitudes (Rossabi, 2005; Sarlagtay, 2002). A local English teacher voiced her frustration and fear by stating that 'children in bilingual schools become trapped between two potentially good worlds. Neither they are perfectly proficient in Mongolian language and culture nor they learn English properly. Their sense of identity...well, they haven't got a proper identity'. Another general understanding and very strong pushing force among the local teachers was that of acting in harmony with the parents' wish, as they wanted their children to 'become good Mongolians'. A teacher said: 'Parents expect us to raise children according to the traditions...to be good Mongolians before everything else. As commented, 'in Mongolia, patriotism and a strong and unambiguous identity is a basic pillar of their culture'.

In sharp contrast with the students' declaring 'cool' the lessons with the foreigners, they did not perceive such classroom scenarios as a positive experience, and they felt 'anxiety for being unable to teach anything because of the noise and chaos'. One of the foreign teacher stated that 'during the first half of the lesson, I just try to silence everybody, however, as soon as I give any order (to open their notebook, or else...) the whole class starts shouting again, walk around and some even get out of the classroom. This is never ending... it feels like they will never understand... I cannot, really just cannot teach anything!' Foreign teachers regularly expressed their wish to change this situation, to learn how to handle students and to develop better teaching and disciplinary strategies. Yet, this positive attitude usually tired out after only a few hours in the beginning of the day. After the lessons, their perspective changed quickly. A teacher declared: 'When I get into the class, I am positive... after a few minutes, I just focus on surviving the lesson, the day, the semester and the school year'. A teacher added: 'Every time I think they respect me a little bit, it takes just a few minutes to see the reality again'. Notably, as it was part of the foreign curricula, foreigners had to teach concepts that would promote students' understanding of global matters. This, according to most of the teachers went 'very unsuccessful'. One teacher stated: They (the students) refuse to understand and learn anything about the world. Any attempt to widen their horizon results in their contra-attack stating how Mongolians are more powerful, have better ideas and are stronger'. The occurrence of such declarations were confirmed by all foreign teacher and were referred as not an isolated incidence.

\section{The Big Picture}

Based on the accounts and observation, most students attributed considerably more power and respect to the local educators regardless of the subject used in the classroom in both schools. On the societal level, the 
Mongolian teachers, being very much aware of the general expectations, learned to fulfil the parents' every wish regarding their child's specific needs, and the ways students are expected to be educated according the Mongolian system (Fairclough, 1989; Poole, 2019). Therefore, if parents' expectations were met, all parties perceived it as 'social balance' that is proper part of 'Mongolness' (Ashcroft, Griffiths \& Tiffin, 1989). Part of this balance was synonymous of speaking the local language (Arazzi, 2014). Their mother tongue, the same language spoken by the parents, the language of the students' heart, in which they interact, dream and express their desires and sorrows, has a deeper emotional impact on them (Kaplonski, 2004). This was clear in most cases, as students assigned more value to their native language and to the local teachers capable of speaking it perfectly, but not to the foreign teachers who were fluent in Mongolian. Clearly, at this point, language, ethnicity and identity were unbreakably associated (Pătraşcu \& Allam, 2017), and language and power became synonymous, even in circumstances that altered this bond for brief instances, such as lessons with foreign teachers (Ashcroft, Griffiths and Tiffin,1989; Fairclough, 1989; Jørgensen, 2006).

Paradoxically, foreign teachers enjoyed more emotional trust and confidence regarding learners' everyday lives, struggles, future plans and their frustration towards the Mongolian education system and local educators (Hanson, 2004). This phenomenon was particularly interesting, since due to many pupils' being deficient in the English language, often the whole meaning and particularly the depth of the communication with the foreigners was entirely lost, or just partly conveyed. This utmost capability of emotional adaptation was previously confirmed by a study on Mongolian students' emotions towards the teachers, which unveils that learners often mirror their teachers' conduct, manners and mood (Komlosi-Ferdinand, 2020). Nevertheless, this skill did not alter their sense of belonging and duty, when their identity, native language and social space had to be prioritised (Bourdieu,1996; Fairclough,1989; Feng Teng \& Lixun, 2020).

The second research question explores the ways linguistic and cultural factors may shape students' identity in bilingual schools. The results unveil how manifestations of teacher-power condition students' national identity, attitudes and understanding towards foreign cultures and their values. Emotions, as a factor of possible divergence or convergence in the bilingual educational panorama is considered, while similarities, contrasts and strategic manoeuvres in teachers' behaviours are explored with the aim of identifying elements for possible future policies for bilingual schools.

\section{Observations}

A very conflicting and tense educational scenario unfolded in both schools. Mongolian teachers, ignoring the bilingual nature of the institutions, strongly reinforced their identity and linguistic power and tried to exercise control over the foreigners' teaching strategies, while foreigners strongly pushed students to think and behave in a 'global' way that placed little importance on their cultural and social values. As a result, learners were entrapped in an environment that, to the contrary of the intended goal by the school, caused divisions and power-games. Students, driven by their national identity, as propelled by local educators, attributed less value to the education by foreign teachers. This was further conditioned by the fact that learners were often disapproved and disheartened by foreign teachers, particularly if their English language skills were not high enough, attributing this to the students' perceived intellectual deficiency. Nevertheless, as foreign teachers' availability out of the classes and less formal attitudes contrasted strongly with local teachers' strict conduct, this attracted students towards developing a more foreign-style behaviour, even having limited comprehension about the foreign language. This duality produced a very interesting outcome, not necessarily in a positive fashion. As there was no existing policy by neither of the schools regarding the psychological features of bilingual education, and learners could observe the tension between the local and foreign teachers, this caused an emotionally negative and chaotic environment.

\section{Students' Opinion}

Learners associated Mongolia and Mongolian teachers with their own identity, yet the foreign teachers' influence and the fact that they had a sense of relax and carelessness with them, promoted their wish to modify their views to a certain degree. A ninth grade student stated: 'I am Mongolian and Mongolia is the best country... but I want to get out of here to study abroad and to live abroad'. When asked, whether they will respect more foreign teachers in a foreign country, the same student replied: 'I do respect foreign teachers...they are cool...we don't have to do much with them, but at least they listen to us.' As the conversation unfolded with several students of the same class, it became clear that they believe that education in countries other than Mongolia were thought to be much easier and undemanding. To illustrate this, a seventh grade student with the utmost 
seriousness asked a foreign teacher: 'Well, actually, I haven't decided yet...what do you think should I pick Oxford or Cambridge?' When asked, most students strongly declined the idea of attending a local university, as it was thought to provide 'worthless and corrupt education'.

\section{Teachers' Opinion}

The current teaching panorama in bilingual schools presents a challenge for teachers. As reported by the local teachers, in traditional Mongolian culture parents allow children (particularly in early childhood) to behave in a very unconfined fashion, regardless of the consequences, expecting these 'sweet' childhood memories to move their offspring in the future to care for them. This behavioural pattern is usually magnified in wealthy families who have more means to support their children's every wish. This attitude is naturally transferred to school, where parents and children expect teachers to display understanding, supportive and even submissive attitudes. Local teachers are well-aware of these expectations and know how to handle specific socio-cultural issues, which at times may seem to be contradictory with the teachers' strictness. However, as having different cultural background and different educational practices, foreign teachers may react unexpectedly and even emotionally to these paradoxical expectations (Heyworth, 2004). In the light of this, Mongolian teachers often rather aggressively reminded both learners and foreign teachers that they were in Mongolia, and education should be embedded in the local culture, according to local values (Rossabi, 2005) and any other instruction can be ignored without consequences. A local teacher stated: 'Yes, I know that this is a bilingual school, and it is okay that kids learn English, but they are Mongolian!' Another local teacher added: 'I always encourage children to respect every teacher...but, you know, they are Mongolians and really have to learn the Mongolian ways first, as this is the society they live in'. Moreover, as many Mongolian teachers declare, lack of strategies and even anarchy are part of their culture (Baabar, 1990), and this can be perceived at the schools as well. The most immediate manifestation of this phenomenon reflects in the lack of consequences of any sort in any domains. A local teacher explained it this way: 'We Mongolians are strong and adapt to everything, this is our culture... and here (in the country and at the schools), believe me, there are many unexpected things happening'. Interestingly, however, this seemed to be addressed mostly towards the foreign teachers, as locals had very low tolerance for 'unexpected' events in their classrooms and daily working routine.

Most foreign teachers were uncomfortable with their Mongolian colleagues' ideas. A foreign teacher stated: 'They invite us here, because they (the school admin) want children to learn from us...but later we are just ignored by everyone.' Foreign educators believed that bilingual education should be seen 'democratically' and that parents would opt for this type of expensive bilingual education because of the foreign presence, and the values attributed to them. Therefore, they often emphasized the importance of 'global-mindedness', which would often manifest itself in creating 'expat' style students, ignoring their cultural background and the fact that their first language, Mongolian, is strongly linked to their traditions and their societal standing (Heyworth, 2004). Additionally, foreigners often complained at an official level about being treated disrespectfully by their Mongolian colleagues in front of the students, which caused anger, frustration and tension in visible ways. A foreign teacher angrily stated: 'Day after day, I arrive to the classroom, but the local teacher refuses to get out...she continues to speak to the kids, collects notebooks...and when I remind her that my lesson has started, she visibly 'suffers' and behaves angrily. This sends a very, very wrong message to the kids'. Another teacher declared: 'The students can see that we are just clowns here...then they treat us as such...they will think that all foreigners are just stupid'.

\section{The Big Picture}

The question of how linguistic and cultural factors in bilingual schools can influence and mould their learners' identity is of particular importance. The aim of bilingual education should not cause divisions and create two restraining forces, but two driving or positive forces towards a healthy language and identity equilibrium as explained by Lewin (1951). The reports from the participants and the observations expose nationalistic behaviour from both groups of teachers (Cohen, 2004; Tamer, Dereli \& Sağlam, 2014), which, in turn, shapes learners' perceptions and attitudes. In fact, children internalising contradictory social and emotional behaviours at school create a foundation for an unhealthy social disposition and a negative emotional milieu, which may affect successful learning (Swain, 2013; Butler 2019; Komlosi-Ferdinand, 2020). Although students reside in their own country, the observed and [sometimes] inspired negative attitudes in bilingual schools may discourage acceptance of diversity. This intolerance for heterogeneity, in turn, may manifest eventually not only in the classroom, but in personal relationships, at future workplaces and in attitudes with people perceived as socially, racially, economically or intellectually different (Hill, 2018). From the foreign perspective, teachers 
are too often helpless when facing such events and have difficulties to design and implement teaching strategies that create balance between cultural needs and global attitudes (Sarlagtay, 2002; Jørgensen, 2006). At the same time, local teachers demonstrate being considerably more knowledgeable on how to manoeuvre in the mentioned educational-cultural maze and its widely accepted and long-standing cultural elements (Hanson, 2004).

The implications of such management involve more than a simple (dis)identification and biased behavioural patterns in Mongolian schoolchildren. As opposed to fostering international mindedness and flexibility of thought, it may endanger students' understanding of societal appropriateness, realistic world-view and may draw biased conclusion on the nature of acceptable emotional and communicational skills, while may nurture classist opinions (Tanu, 2016; Schippling, 2018). Currently, the bilingual education system in Mongolia shows traces of these fossilised behaviours and practice (Cravens, 2018). Moreover, if bilingual education and 'global mindset' are perceived only as a symbol of status for the parents, yet, within the schools 'Mongolian ways' are encouraged [and not in the sense of intellectual capital, but nationalism], the real purpose, value and potentially positive outcomes are easily lost. This loss can be considered even greater, if the result and consequence of such practices, instead of encouraging, discourages the learners' curiosity, love for diversity and cultural tolerance (Koh, 2014).

It is of key importance to state that most of the learners graduating from these institutions intend to study abroad, which makes it difficult to comprehend the lack of strategies offered by the schools to overcome the confusion, and to aim for more balance in developing appropriate perceptions about languages and identity (Fearon, 1999; Heyworth, 2004). On the other hand, a particularly thought-provoking contrast can be observed in Mongolian learners' attitudes and perceptions towards foreign languages and cultures in bilingual versus national educational systems. A previous study amongst Mongolian learners from the mainstream education system reported very positive attitudes, open-mindedness and flexibility towards foreign languages, cultures and their speakers (Komlosi-Ferdinand, 2019). Therefore, it becomes clear that the problem may not lie in the Mongolian society itself but the erroneous power practices allowed in bilingual schools attended by homogeneous, local children.

Such identity struggles are not unique to Mongolian schools, as bilingual education is always embedded in a sociolinguistic, political, cultural and philosophical context and it rarely reflects only educational preferences or curriculum choices (Baker, 2011; Appel \& Muysken, 1987). This occurrence is well confirmed by an identical scenario reported by Fader (2007, p. 12) in a Hasidic school in New York. According to his report, children took more seriously and respected more the educators conducting their lessons in Yiddish, as opposed to teachers teaching subjects through the medium of English. In fact, during an interview an eleven-year-old student declared about his English teacher: 'S'iz nisht kan teacher. S'iz a babysitter' ['That's not a teacher. That's a babysitter']. Somewhat similarly, in the Mongolian bilingual educational context, three coexisting social and cultural spaces were found, such as the local teachers, foreign teachers and the students, who already belonged to a peculiarly and unevenly mixed social space. It was, in fact, expected to have some minor misunderstandings based on cultural and linguistic differences, which could be seen as natural and not necessarily negative in any similar scenario. However, the behaviour of the local teachers confirmed well Bourdieu's (1998) symbolic violence theory, as Mongolian teachers vigorously exercised it, or at least attempted to do it, in the general teaching panorama against both students and foreigners. The Mongolian teachers were undoubtedly perceived as the higher social class and the bearers of the stronger cultural capital because of their knowledge of the students' culture, language and the strong collaboration with the parents. However, the cultural and educational differences displayed by the foreign teachers and the unconventional behaviour and attitudes of the students triggered (consciously or not) strong symbolic violence from them, possibly trying to nurture the social space considered proper by them and the parents. Here, by no means the foreign teachers are 'victimised', but rather the students, who would, or already have become confused regarding their own social spaces and status, and did not embrace the new, flexible and wider perceptions which the schools should have fostered. Furthermore, the Mongolian teachers' dominance in their field has strongly reinforced Bourdieu's (1990) habitus theory confirming Mongolian educators' role in shaping and strengthening early concepts of identity and their role in future behaviours and opinions. This became clear, as students' value system and responses often reflected the local teachers' attitude and thought processes, in perceiving foreign educators as deserving less respect and requiring less seriousness and effort in their classes. While the habitus theory describes perfectly the ways proper cultural and ethical standards can be instilled in students, in this particular case it manifested in a 
'resistance-habitus' against the foreign teachers and the global values intended to be promoted by the schools. Therefore, the Mongolian teachers' attitude would have been understandable in the national educational system, but by no means in a bilingual educational context aiming to promote globalness. On the other hand, the foreign teachers' lack of knowledge and training of the local culture may have involuntarily triggered a stronger response in their Mongolian colleagues. Here, the responsibility of the schools clearly surfaces, as such complications must be identified, addressed and proper training and policies must be developed.

The present study identified some critical factors that determine, modify and/or bias learners' identity and attitudes towards local and foreign educators in Mongolian bilingual schools. Nowadays in Mongolia, bilingual schools' ethnic composition shows an almost completely homogeneous student population, and bilingual education is mostly manifested by the presence of foreign teachers, who embody the 'the other side' or the expected source of global education. The findings reveal that students' national identity is a crucial factor that differentiates their attitudes towards local and foreign teachers. On a daily basis, learners manifested noticeably more fear from, and respect towards local teachers, and the discipline and more positive learning outcome in their classes were obvious. The Mongolian teachers, being knowledgeable about the social expectations and the parents' wishes, educated learners according the Mongolian system (Fairclough, 1989; Poole, 2019). This was perceived very positively by them and the parents, as it was viewed as the manifestation of social 'balance' that is proper part of 'Mongolness' (Ashcroft, Griffiths \& Tiffin, 1989). The pillar of this balance was speaking the local language, synonymous to identity according to them (Kaplonski, 2004; Arazzi 2014). The inseparableness of language and identity was also manifested in the fact, that foreign teachers, even those who were capable to understand and speak Mongolian, were not taken seriously and were often ridiculed. Therefore, race and identity were unshakably associated, and power and language became commensurate (Ashcroft, Griffiths, \& Tiffin,1989; Fairclough, 1989; Jørgensen, 2006). On the other hand, foreign teachers were perceived positively, but not seriously. As they were considered more outgoing and less strict, respect towards them was shown mostly in an emotional, friendly fashion, while their educational requirements were completely ignored, as often they were considered 'weaker' in comparison with the local teachers. Students' perception about the two groups of educators in their professional quality was heavily influenced by their national identity and by the social space and status (Bourdieu, 1996) reinforced and promoted by the local educators. Moreover, while their positive emotional attitude towards foreigners seemed not to alter their mindset and identity considerably (Fairclough,1989; Feng Teng \& Lixun, 2020), it created a special social space not fully coinciding with the one intended by the Mongolian teachers. As seen, emotions, identity, language and power were heavily intertwined and proved to be the decisive factor that conditioned many of the decisions and attitudes in the schools (Ashcroft, Griffiths \& Tiffin, 1989; Jørgensen, 2006; Swain, 2013; Arazzi, 2014; Butler, 2019).

Very specific elements were identified that shape learners' identity and further cognitive and behavioural development in bilingual schools. Most importantly, local teachers could interact with pupils in their native language, the language of their hearts, which played essential part in their identity formation and is considered as an essential part of their culture. This confirmed Bourdieu's (1990) habitus theory, with particular emphasis on how learners' developing value system was conditioned by their ethnic, cultural and social background. In both schools, students received considerable pressure from local teachers to strengthen and further develop this habitus. Nevertheless, for learners manoeuvring between the local societal and cultural expectations and the foreign influence often led to confusion and inappropriate behaviour. This, as opposed to an ideal state described in Lewin's force-field theory, showed two pushing forces. Here, instead of moving towards a balanced state, students are pushed into two completely different directions, thus alienating any possible point of convergence between the two languages, cultures and the opportunity of developing a new global aspect of the pupils' identity. The presence of these two pushing forces created distress among the teachers as well. In line with Bourdieu's (1998) symbolic violence theory, locals exercised considerable symbolic violence on both learners and foreign teachers. In reality, local and foreign educators intended to provide the best educational strategies known by them, yet they proceeded according to their culturally acceptable approach, without proper understanding, tools and policies to stabilize the impending linguistic and cultural shock faced by the students. This phenomenon led to an academically and emotionally imbalanced environment in the schools. Therefore, the initial objective of educating bilingually and bi-culturally competent and balanced global-minded individuals has failed. 


\section{Conclusion}

The present research has identified some key areas for improvement in bilingual schools. Since in a growing number of countries bilingual education has no real bilingual context and culture, and learners are from the same ethnic/linguistic background, the creation of new educational strategies is urgently needed. Both local and foreign teachers should attend specific inter-cultural courses especially designed for the educational panorama of the target country. Learners should have readily available resources and discussions with teachers and school psychologist, where foreign language and culture-related emotional intelligence and appropriate behaviours are taught. Moreover, school administration should design and display clear policies on the nature and aims of bilingual education, which is respectful towards the local culture, yet highlights the benefits of bilingualism and its cognitive and cultural advantages. While this study offers some insight into the drama of language and identity in bilingual schools in Ulaanbaatar, it is limited by its geographical location and by the specific culture where it was investigated. Further research is much needed on educational leadership in bilingual schools and the development of intercultural literacy courses. Finally, in Rhydwen's (1998, p.101) words: 'Language...is intimately connected with people and it cannot be treated simply as an intellectual puzzle to be solved.'

\section{Acknowledgements}

I am very thankful to all my Mongolian and foreign colleagues for their (sometimes drastically) honest answers, their time at the end of the day and their tolerance for my curiosity. I am also in debt with the participating students, who helped me with their sincere opinions or ignored me completely, so I could observe them without interference. Маш их баярлалаa! (Thank you very much)!

\section{References}

Appel, R., \& Muysken, P. (1987). Language Contact and Bilingualism. Edward Arnold.

Arazzi, W. E. (2014). Language and power in the media: The Geoff Hunt murder-suicide [Unpublished paper]. https://www.researchgate.net/profile/Emma_Campbell44/publication/301302890_Language_and_Power_in_ the_Media/links/571181d508ae4ef74524b40b/Language-and-Power-in-the-Media.pdf

Ashcroft, B., Griffiths, G. \& Tiffin, H. (Eds.) (1989). The Empire Writes Back: Theory and practice in post-colonial literatures. Routledge.

Baabar. (1990). Büü Mart! In D. Snaeth \& C. Kaplonski (Eds.) The history of Mongolia (1028-1038) (vol. 3, pp. 1001-1011). Global Oriental. https://doi.org/10.1163/9789004216358_053

Baker, C. (2011). Foundations of bilingualism and bilingual education. Multilingual Matters.

Bourdieu, P. (1990). In other words: Essays towards a reflexive Sociology (M. Adamson, Trans.). Stanford University Press.

Bourdieu, P. (1990b). The logic of practice (R. Nice, Trans.). Stanford University Press.

Bourdieu, P. (1996). Physical space, social space and habitus [Lecture notes]. https://archives.library.illinois. edu/erec/University\%20Archives/2401001/Production_website/pages/StewardingExcellence/Physical\%20 Space,\%20Social\%20Space\%20and\%20Habitus.pdf

Bourdieu, P. (1998). Practical reason: On the Theory of action. Stanford University Press.

Bunnell, T. (2019). International schooling and education in the 'New Era': Emerging issues. Emerald.

Butler, Y. O. (2019). Linking noncognitive factors back to second language learning: New theoretical directions. System, 86, 102-127. https://doi.org/10.1016/j.system.2019.102127

Cohen, R. (2004). The current status of English education in Mongolia. Asian EFL Journal, 6(4), 1-29.

Cohen, L., Manion, L., \& Morrison, K. (Eds), 2018. Research methods in education. Routledge.

Cravens, X. (2018). School leadership in international schools: Perspectives and practices. Peabody Journal of Education, 5, 584-588. https://doi.org/10.1080/0161956X.2018.1515818

Dos Santos, L.-M. (2019). Recruitment and retention of international school teachers in remote archipelagic countries: The Fiji experience. Educational Sciences, 9(132), 2-16. https://doi.org/10.3390/educsci9020132 
Fader, A. (2007). Reclaiming sacred sparks linguistic syncretism and gendered language shift among Hasidic Jews in New York. Journal of Linguistic Anthropology, 17(1), 1-22. https://doi.org/10.1525/jlin.2007.17.1.1

Fairclough, N. (1989). Language and power. Longman.

Fearon, J. D. (1999). What is identity (as We Now Use the Word)? [Draft]. https://web.stanford.edu/group/fearonresearch/cgi-bin/wordpress/wp-content/uploads/2013/10/What-is-Identity-as-we-now-use-the-word-.pdf

Feng Teng, M., \& Lixun, W. (2020). Identity, motivation and multilingual education in Asian Contexts. Bloomsbury Academic

Hanson, J. (2004). Nations in transition: Mongolia. Facts on File.

Heyworth, M. (2004). Intercultural Literacy and the International School [Doctoral thesis, University of Tasmania]. Tasmania. https://eprints.utas.edu.au/423/2/02Whole.pdf.pdf

Hill, I. (2015). What is an 'International School'? International Schools Journal, XXXV(1), 60-70.

Hill, I. (2018). A subjectivist model of school leadership for international schools: Greenfield revisited. Peabody Journal of Education, 93(5), 1-16. https://doi.org/10.1080/0161956x.2018.1515827

Hycner, R. H. (1985). Some guidelines for the phenomenological analysis of interview data. Human Studies, 8 , 279-303. https://doi.org/10.1007/BF00142995

Jørgensen, K. M. (2006). Power and language. Aalborg Institut for Uddannelse.https://vbn.aau.dk/en/publications/ sprog-og-magt

Kaplonski, C. (2004). Democracy comes to Mongolia. In D. Snaeth \& C. Kaplonski (Eds.), The history of Mongolia (1039-1050) (vol. 3, pp. 1039-1059). Global Oriental. https://doi.org/10.1163/9789004216358_057

Koh, A. (2014). Mobile Curriculum. In Arber, R., Blackmore, J. \& Vongalis-Macrow, A. (Eds.), Mobile teachers, teacher identity and international schooling (pp. 25-41). Sense Publishers.

Komlosi-Ferdinand, F. (2019). New Language -New Emotions? The Role of Emotional Intelligence While Learning Foreign Languages in Mongolia. Mongolian Journal of English Langauge and Culture Studies, 9, 20-33.

Komlosi-Ferdinand, F. (2020). Academic emotions and emotional validation as motivating and demotivating factors in the ESL classroom: A Mongolian case study. REIRE Revista d'Innovació $i$ Recerca en Educació, (13)1, 1-21. http://doi.org/10.1344/reire2020.13.127522

Lewin, K. (1951). Field theory in social science. Harper \& Row.

May, T. M. (2009). Culture and customs of Mongolia. Greenwood Press.

Meneghella, K., Walsh, J., \& Sawagvudcharee, O. (2019). Strategies to maximise staff retention among millenial teachers in Bankok international schools. Asian Social Science, 15(8), 70-85. https://doi.org/10.5539/ass. v15n8p70

Milošević, O. (2019). The Importance of mother tongue maintenance in international schools. Nastava $i$ Vaspitanje, 68(2), 251-263. https://doi.org/10.5937/nasvas1902251M

Pătraşcu, E., \& Allam, M. (2017). Language of power and world peace. In Debating globalization. Identity, Nation and Dialogue (pp. 167-172), Tîgru Mures. https://www.researchgate.net/publication/338161767_LANGUAGE_ OF_POWER_AND_THE_WORLD_PEACE

Poole, A. (2019). Teacher (in)discretion in international schools. On Education Journal for Research and Debate, 2(5), 1-5. https://doi.org/10.17899/on_ed.2019.5.1

Rhydwen, M. (1998). Strategies for doing the possible. In N. Olster (Ed.), Endangered Languages: What role for the specialist? Proceedings of the Second FEL Conference, University of Edinburgh (pp. 25-27). Foundation for Endangered Languages.

Rossabi, M. (2005). Modern Mongolia. University of California Press.

Sarlagtay, S. O. (2002). Current Mongolian cultural problems: Internal and external. The Mongolian Journal of International affairs, 8(9), 99-105.

Schippling, A. (2018). Researching international schools: Challenges for comparative educational research. Revista Lusofona de Educação, 41, 193-204. https://doi.org/10.24140/issn.1645-7250.rle41.12

Swain, M. (2013). the inseparability of cognition and emotion in second language learning. Language Teaching, 46(2), 195-207. https://doi.org/10.1017/S0261444811000486

Sweeney, C. (2017). Social class, habitus and reflexivity: An analysis of trainee teachers' understandings [Unpublished doctoral thesis]. University of Brighton.

Tamer, I., Dereli, B. \& Sağlam, M. (2014). Unorthodox forms of capital in organizations: Positive psychological capital, intellectual capital and social capital. Procedia - Social and Behavioral Sciences, 152, 963 - 972.

Tanu, D. (2016). Unpacking 'Third Culture Kids': The transnational lives of young people at an international school in Indonesia. Journal of Research in International Education, 15(3), 275-276. https://doi. org/10.1177/1475240916669081

Thomas, D. R. (2006) A general inductive approach for analysing qualitative evaluation data. American Journal of 


\section{FLORA KOMLOSI-FERDINAND}

Education, 27(2), 237-46. https://doi.org/10.1177/1098214005283748

Wang, Y. (2012). Ethical intervention versus capital imaginaries: A class analysis of the overseas schooling choice of the Chinese 'New Rich'. Joint AARE APERA International Conference, Sydney. https://files.eric. ed.gov/fulltext/ED542343.pdf

Weenink, D. (2008). Cosmopolitanism as a form of capital: Parents preparing their children for a globalising world. Sociology, 42(6), 1089-1106.

Weininger, E. (2005). Pierre Bourdieu on social class and symbolic violence. In E. O. Wright (Ed.), Approaches to class analysis (pp. 119-171). Cambridge University Press.

Wragg, E. C. (1978). Conducting and analysing interviews. University of Nottingham, School of Education, TRC Rediguides.

Wragg, E. C. (1999). An introduction to classroom observation. Routledge. 